\title{
VERDADE E INÉRCIA SEMÂNTICA: ELEMENTOS PARA A FUSÃO DA SEMÂNTICA COM O PRAGMATISMO
}

Lucas Ribeiro Vollet ${ }^{1}$

\begin{abstract}
Resumo
O artigo pretende enunciar os elementos teóricos em que uma fusão entre a semântica e o pragmatismo emerge. Essa conclusão progride através de uma série de teses intermediárias: a de que o valor semântico não pode ser explicitado pelo estudo de uma relação de designação ou mapeamento recursivo (tese anti-mecanicista do significado); a de que a semântica controla normativamente o acesso à noção de verdade e de validade (tese do caráter regulativo da semântica); a de que o valor semântico de duas sentenças pode ser extensionalmente idêntico, embora intensionalmente divergente (a tese intensional); a de que é possível prever essa divergência de comportamento intensional (a tese de que a intensão não é mística); a tese de que a predição de comportamento intensional compõe um estudo da receptividade sensível da língua a possíveis verificadores (tese da diferença entre verdade e verificação); a tese de que o fundamento semântico de uma sentença está ligado à sua sensibilidade receptiva e a de que a semântica estuda meios de prever diferenças de apoio dos verificadores possíveis quando entram em contextos teóricos ou linguísticos incongruentes (tese do potencial inercial). Essas teses nos levarão às primícias de um estudo do que chamaremos de "inércia semântica", que dará oportunidade para argumentar a favor de uma fusão do pragmatismo com a semântica para estudar as formas como estratégias inferenciais, hipóteses de interpretação e tradução são alavancadas regulativamente, facilitando certas direções inferenciais em detrimento de outras.
\end{abstract}

Palavras-chave: Semântica, Intensão, Pragmatismo, Verdade.

\section{TRUTH AND SEMANTIC INERTIA: ELEMENTS FOR THE FUSION OF SEMANTICS WITH PRAGMATISM}

\begin{abstract}
The article intends to state the theoretical elements in which a fusion between semantics and pragmatism emerges. This conclusion progresses through a series of intermediate theses: that the semantic value cannot be explained by the study of a relation of designation or recursive designation (anti-mechanistic thesis of meaning); that semantics normatively controls access to the notion of truth and validity (thesis of the regulatory character of semantics); that the semantic value of two sentences can be extensionally identical, although intensionally divergent (the intensional thesis); that it is possible to predict this divergence of intensional behavior (the thesis that the intension is not mystical); the thesis that the prediction of intensional behavior composes a study of the sensitive receptivity of the language to possible verifiers (thesis of the difference between truth and verification); the thesis that the semantic foundation of a sentence is linked to its receptive sensitivity; and that semantics studies ways of predicting differences in support from possible verifiers when they are inserted in incongruent theoretical or linguistic contexts (thesis of inertial potential). These theses will take us to the beginnings of a study of what we will call "semantic inertia", which will give an opportunity to argue in favor of a fusion of pragmatism with semantics to study the ways in which inferential strategies, hypotheses of interpretation and translation are regulated, facilitating certain inferential directions at the expense of others.
\end{abstract}

Keywords: Semantics, Intension, Pragmatism, Truth.

1 Possui graduação em filosofia pela Universidade Federal de Santa Catarina (2008), mestrado em Filosofia pela Universidade Federal de Santa Catarina (2011), e doutorado em Filosofia (2016) pela mesma Universidade, atuando principalmente no seguinte tema: juízo, razão prática, validade, ciência. E-mail: luvollet@gmail.com. http://orcid.org/0000-0002-6300-491X 


\section{A complexidade da relação entre semântica e verdade: as limitações de uma abordagem formal e mecânica para definir a validade}

Apesar de algumas décadas de produção acadêmica terem obscurecido a diferença entre elas, a unificação da teoria semântica com a temática sobre a verdade não tem aquela espécie de evidência que nos confortaria sem cobrar nada. Já não está tão próxima de nós aquela antiga crença metafísica de que o estudo direto da realidade nos daria algo parecido a uma teoria sobre toda verdade possível, em seus elementos mínimos, ou seus estados de informação máximos: por exemplo, as informações mais gerais sobre tudo o que é. Essa crença chegou à semântica formal apenas em seu molde mais artificial. A realidade é reduzida a um valor algébrico: é isso ou aquilo, a depender de como escolhemos preencher as variáveis proposicionais. Chamá-la de realidade já é desnecessário, porque não passa de uma projeção ou uma escolha teórica sobre correlações entre variáveis. Essa caracterização pode pecar contra ambições de representação ampla do real, mas não é injusta com o modo de representação científica-nomológica pós-empirista.

Porém, há motivos novos para duvidar de que o mecanicismo semântico formal possa dar todas as respostas aos problemas que a antiga metafísica dispunha. Os ganhos de esclarecimento, simplificação e neutralidade dificilmente vem com uma compensação na dimensão da segurança. Micheal Dummet, em The Logical Basis of Metaphysics (1991), levou a reflexão sobre a relação entre semântica e verdade até o caso mais caro à lógica: a inferência. Durante o capítulo dois, o autor nota e chama atenção ao fato de que a noção de verdade, entendida como uma designação derivada do conceito algébrico de satisfação de uma variável, não é capaz de cumprir com competência a tarefa lógica mínima: preservar a verdade das premissas à conclusão:

Nós podemos chamar definições de validade desse gênero de definições em termos de verdade (designação). Elas geram inúmeras esquisitices. Por causa disso, nós podemos muito bem duvidar de que a verdade realmente seja a noção central para a caracterização de inferências válidas. (Dummet, 1991, p. 41).

Quando praticamos inferências, de fato, não é incomum precisarmos de uma razão para justificar a presença da conclusão, se as premissas forem verdadeiras. Mas quando definimos a validade como a simples presença material, no universo de discurso pertinente, da verdade (designação) do antecedente e do consequente no universo, perdemos a capacidade de justificar a conclusão sem a ajuda de exemplos. A princípio, essa miscigenação inusitada entre lógica e ciência empírica é uma inconveniência inofensiva. Uma tabela de verdade pode ser

\begin{tabular}{|l|l|l|l|l|}
\hline Qonista Oialectus & Ano 10 & n. 23 & Maio - Agosto 2021 & p. 348 - 364 \\
\hline
\end{tabular}


montada para mostrar que nenhuma interpretação possível das premissas e da conclusão teria instâncias da primeira verdadeira e da segunda falsa. Isso retira a aparência de ciência empírica que a semântica parece dar à lógica. Mas não elimina outro problema: a capacidade da lógica de identificar e se proteger de falácias. Pois não é difícil montar, ao modo de trapaças, esquemas de substituição ou distribuições de estados completos em que é excluído o único caso (designação) capaz de falsear uma implicação material na tabela de verdade. Esse tipo de facilidade de gerar conclusões não é o que se espera da investigação científica responsável. Se é fácil montar esquemas de validade artificiais, é muito mais fácil produzir falácias que não podem ser excluídas apenas pela sua forma. D.C. Stove em The Myth of Formal Logic, mostrando que instâncias da falácia do termo médio não distribuído e da afirmação do consequente podem ter suas variáveis substituídas de modo a produzir um argumento válido, sugere que: "será sempre possível escolher valores dessas variáveis que produzem uma instância válida das formas em questão. Não há, resumindo, essa coisa de 'falácia formal' como a frase é geralmente entendida" (1986, p. 118).

O exemplo de Stove envolvia a conexão significativa entre "father" e "male parent", que fez o truque de suplementar a conclusão de que Hume é um 'male parent' se (P1) todos os 'male parents' são ‘fathers' e (P2) Hume é um 'father'. A forma desse argumento é geralmente inválida, porque o meio termo não está distribuído, isto é, "father" (o termo médio) não liga Hume a male parent; mas com o nosso truque, ela se tornou imune a contraexemplos: não há interpretações da inferência em que a conclusão seja falsa e as premissas verdadeiras. Apesar de "não distribuído", o termo médio está conectado a Hume e a male parent em qualquer caso possível, derivando uma coincidência superficial, mas suficiente para os propósitos da inferência. A forma lógica representa uma tese dedutiva puramente extensional que deriva a conclusão da ausência de casos contrários. Analisemos agora o truque. A conexão conclusiva, alguém poderá dizer, foi adquirida por um truque semântico, já que as instâncias de 'male parent' e 'father' coincidem extensionalmente em um sentido que é irrelevante para derivar conclusões sobre Hume. Se avaliássemos indutivamente a conclusão, poderíamos descobrir que apesar de Hume ter em comum com male parent uma propriedade (father), isso só garante uma coincidência externa, que mesmo que seja obtida em qualquer mundo possível (não há mundos em que Hume seria father e não male parent), não garante a conexão no estado normativo que esperaríamos se quiséssemos uma inferência científica do mesmo tipo que conecta o açúcar à solubilidade na água. Mas o lógico formal acha isso uma vantagem histórica de seu legado: não se preocupar com conexões causais e outras formas de inferências de baixo nível de

\begin{tabular}{|l|l|l|l|l|}
\hline Q Rovita Dialectus & Ano 10 & n. 23 & Maio - Agosto 2021 & p. 348 - 364 \\
\hline
\end{tabular}


generalidade. Stove contra-argumenta: o lógico formal advoga sua superioridade sobre a ciência empírica justamente no aspecto em que ele está mais vulnerável a falácias de toda sorte: “o lógico formal coloca sua mira na alta generalidade. (...) Generalidade desse alto grau está presente no julgamento de que todos os casos do 'meio termo não distribuído', ou da 'afirmação do consequente', são inválidos. Mas, como vimos, esses julgamentos de invalidade são falsos" (Stove, 1986, p. 123). O preço da alta generalidade, em lógica, é que essa disciplina é muito mais vulnerável a confecção de paradoxos do que a ciência empírica. Há diversos motivos para concluir que aquela inferência, apesar de formalmente válida, não exprime o fim conclusivo de uma investigação e apresenta apenas a ausência de casos contrários como elemento fundante.

O lógico formal poderia retrucar dizendo que esse defeito é facilmente evitável. Por que alguém colocaria "father" como termo-médio não distribuído em uma inferência, se ele pode adquirir o mesmo resultado conclusivo sem esse artifício, simplesmente dizendo que Hume é father logo Hume é um male parent? Essa pergunta toca os sinos certos. Mas ela apoia o argumento de Stove. A defesa do lógico formal toma aqui a forma de uma crítica a ele mesmo: ele está dizendo que nem todo argumento válido para todas as substituições possíveis de variáveis são exemplos de conexão argumentativa relevante. E isso se alinha à resposta que Stove está esboçando contra o mito das vantagens da alta generalidade. Alguém pode acreditar formalmente que Hume é um 'male parent' porque é um 'father', mas ele precisa prová-lo. Se para prová-lo ele usa "father" como termo médio de um silogismo, e o coloca na forma da falácia do 'meio-termo não distribuído', isso seria uma escolha de argumentação exótica, tão amplamente geral que alguém poderia desconfiar de que não passa de um truque de esquiva. Ora, a lógica formal está cheia desses exotismos: conclusões lógicas apenas porque não podemos preencher as variáveis de modo a produzir uma tabela de implicação material falsa. Nesse exemplo de resposta, o lógico formal terá reflexivamente descoberto ou reconhecido que as formas lógicas são escolhas exóticas de formulação argumentativa. A estratégia de defesa do lógico formal acaba sendo mais uma autocrítica reflexiva do que uma advocacia bem sucedida. Na prática, pode ser importante para esclarecer a dependência que a conclusão tem da premissa vê-la representada em uma forma; mas isso não exclui o fato de que a conexão conclusiva é de uma natureza mais essencial (normativa) do que a meramente extensional, e o formalismo não vai além do último. O truque de Stove, portanto, mostra uma limitação do formalismo extensional. Mas será que é assim que argumentamos na vida real? Na verdade, argumentamos assim com frequência apenas quando estamos mais interessados em escapar de objeções, sem estarmos completamente seguros de nosso fundamento conclusivo. $\mathrm{O}$ formalismo define um

\begin{tabular}{|c|c|c|c|c|}
\hline Qovista Dialectus & Ano 10 & n. 23 & Maio - Agosto 2021 & p. $348-364$ \\
\hline
\end{tabular}


tipo de argumentador que confunde economia com preguiça: se ele tem convicção de que o oponente não irá construir um contraexemplo ao seu argumento, por que procuraria um fundamento mais firme à conclusão?

$\mathrm{O}$ que isso sugere é que podemos montar esquemas artificiais e falaciosos de validade facilmente, porque a própria generalidade ampla e irrestrita das variáveis facilita a escolha de instâncias substitutas que não estão relacionadas por regra alguma; ou melhor, são relacionadas pela mera forma da regra. O que aprendemos com Stove, a nosso ver, tem mais consequências frutíferas para o estudo da semântica do que do problema da indução ${ }^{2}$. É que a facilidade da forma lógica para gerar representações de inferências pela impossibilidade extensional de certas combinações não ajuda enquanto não possamos aplicar uma regra a essa exclusão: não ajuda, enquanto não podemos dizer o que torna o caso falseador da implicação “impossível”; e, finalmente, o que para nós é o mais importante (até o final do artigo ficará claro porquê): não ajuda a mostrar em que custo, resistência ou pressão (inércia) essa propriedade modal (a impossibilidade) se funda. Apenas quando chega a um conhecimento do último nível, a nosso ver, se tem um conhecimento do fundamento semântico da validade. Se nossa teoria semântica não consegue prever a diferença entre uma inferência cuja conclusão é necessária e uma em que não é, ficamos presos no reino vazio da formalidade. Ficamos sempre, assim, dependentes de mais justificação. Foi esse primeiro impulso que levou à concepção das primeiras lógicas-modais ${ }^{3}$ e há algo no construtitvismo intuicionista inspirado na mesma insatisfação ${ }^{4}$.

A neutralidade da semântica formal e o desafio a que ela não responde: como normativizar a ordem que relaciona sentenças em relações de validade

Ainda que os problemas anteriores não fossem suficientes, hoje não está fora do alcance mesmo dos pensadores menos propensos à parte mais formal do estudo lógico, encontrar provas de que sentenças não ganham uma caracterização automática ou mecânica como premissa e conclusão apenas pela sua "forma". A forma apenas ajuda a esclarecer como

2 Justificar a racionalidade da indução era o foco principal do autor no livro mencionado (The Rationality of Induction), e no capítulo citado, seu projeto era mostrar as limitações da definição formal do raciocínio dedutivo.

3 "A motivação original do desenvolvimento feito por Lewis da lógica modal foi a insatisfação com a noção de implicação material” (Haack, 2002, p. 236).

4 Ver Quine em Sobre o que Há: "o intuicionismo (...), assegura o emprego de variáveis ligadas para referência a entidades abstratas apenas quando essas entidades podem ser preparadas de antemão a partir de ingredientes especificados" (1980, p. 225)

\begin{tabular}{|c|l|l|l|l|}
\hline Govista Dialectus & Ano 10 & n. 23 & Maio - Agosto 2021 & p. $348-364$ \\
\hline
\end{tabular}


o conteúdo da argumentação pode ser retirado na formulação da estrutura relevante para a avaliação de sua verdade. Isso, contudo, representa nada mais que uma escolha: cada argumentação é estruturada para selecionar aquilo que ela excluirá da lista de dependência para sua validade. Nada impede, por princípio, selecionar substituições de variáveis que fariam falácias como a do "meio termo não distribuído" não serem inválidas. O formalismo pode escapar a essa crítica apenas fazendo pressuposições analíticas sobre as restrições à substituição; mas com isso já se rende: admite que não soluciona questões de validade sozinho. Quando se rende a restrições sobre os ingredientes regionais que permitem construir a prova, evita objeções intuicionistas, mas se submetendo às suas exigências. A questão da restrição ou relativização de substituição nos leva a um importante aspecto da crítica ao extensionalismo clássico e à semântica formal: uma semântica intuicionista tem entre suas motivações justamente dar uma base que permitiria construir a falsidade da contraditória de uma sentença verdadeira. Mas o intuicionismo vai só até um limite; não é capaz de abstrair o valor intensional que dá à identidade construída uma distância normativa e regular diante de tudo o que se diferencia dela. E é isso o que esperamos de uma semântica, como a defendemos.

A bipolaridade sentencial é uma peça disputada por qualquer teoria semântica. Nesse artigo, sugerimos que a distância entre a verdade e a falsidade não é pressuposta formalmente pela lei do meio excluído, e tampouco por um simples princípio construtivo. Ela é constituída pelo programa de acúmulo semântico que coloca todo apoio possível a uma proposição do mesmo lado da linha que apoia todas as proposições com ela compatíveis. Esse programa de acúmulo semântico é uma teoria intensional. Isso nos ajudaria a justificar a prova da inferência de Stove, mostrando que o todo acúmulo de apoio intuitivo a "Hume é male parent" pertence à mesma classe de apoio à "Hume é father", porque podemos codificar uma regra para ordenar o alinhamento dos apoios semânticos sempre em uma direção que não contraria essa conclusão. Assim, ao fazer uma inferência, não fazemos mais do que aproveitar os resultados desse alinhamento regular para ordenar os elementos da conclusão de uma forma derivada diretamente das premissas. Para alguém dizer com competência que sabe como operar essa inferência, é preciso saber ordenar essa relação entre ambas, e isso a mera designação de verdade não pode fazer. A lógica clássica passou sem precisar se preocupar com isso porque suas pré-noções semânticas nasceram de sofisticações matemáticas que já incluíam a possibilidade de ordenação e correlação. Mas sempre quando passamos à linguagem ordinária e a conteúdos não obviamente numéricos, nem traduzíveis por números e relações biunívocas, esse tipo de designação para definir a validade rui. Teorias intensionais são as únicas capazes

\begin{tabular}{|l|l|l|l|l|}
\hline Govista Dialectus & Ano 10 & n. 23 & Maio - Agosto 2021 & p. $348-364$ \\
\hline
\end{tabular}


de prever o comportamento da verdade para além da mera designação ou mapeamento mecânico. Isso não mostra senão que a transição da verdade para a validade é tão complicada e filosoficamente hermética quanto a dos fatos para as normas, ou do efetivo para o deontológico.

Encontramos um chão firme para a afirmação de Dummet, de que: "o que a lógica precisa é, preferencialmente [à designação] uma relação de estar mais próxima à verdade" (1991, p. 41). A proximidade é, naturalmente, uma relação, e sugere que seja regulada ou ordenada segundo uma regra de progressão que a diferencia da falta de proximidade. Quando obtemos essa relação, a natureza da inferência deixa de ser meramente baseada na designação direta, e passa a ter uma natureza prescritiva. A exposição de Dummet de que definir a validade em termos de designação ou escolha de substituição é limitada, rememora uma antiga limitação do predicado "verdade". A saber, a sua pobreza prescritiva. Isso nos leva a uma bifurcação, e temos que escolher. A contribuição semântica da designação de valores isolados às sentenças é conveniente se não queremos acrescentar à interpretação das sentenças algum conteúdo normativo. Se queremos estar à altura do critério composicionalista técnico, não podemos acrescentar normas que suplementem o significado das sentenças, pois isso seria depender de mais do que a sentença significa ${ }^{5}$. Porém, com isso ficamos empobrecidos para construir inferências, porque dependeríamos sempre de ter uma "forma" disponível para isso. Mas falemos porque esse regime de pobreza voluntário foi tão popular. O motivo mais óbvio é que é conveniente, como queria Tarski, selecionar apenas o tipo de teoria da verdade capaz de derivar instâncias das sentenças que padronizam uma relação com verificadores neutros com relação a leis e regras; a forma é o molde para qualquer regra. Isto é, quaisquer leis ou padrões sintáticos que codificam as instâncias de esquemas-T, para Tarski, são tão efetivas quanto quaisquer outras: não há privilégio gramatical ou simbólico de uma cultura ou linguagem sobre qualquer outra para regular. O autor evita a metafísica pela raiz. Porém, o preço é o que foi mencionado: até para definir a validade esse tipo de estratégia é limitada, e se quisermos definir a "analiticidade", entramos em limitações ainda maiores - como os próprios extensionalistas reconheceram, sendo obrigados no fim a renunciar ao termo "analítico".

Os pensadores que optaram por admitir operadores de implicação estrita demonstraram a insatisfação da noção de validade puramente material, precisamente pois a matéria semântica neutra não gera um conhecimento sobre a impossibilidade de ser de outro

5 Ver Davidson: "uma teoria recursiva da verdade absoluta, como requerida pela convenção T, oferece resposta a um problema diferente. Esse problema pode ser expresso como aquele de mostrar ou explicar como o significado de uma sentença depende do significado de suas partes" (Davidson, 2001, p. 70). 
modo. Ela não gera um conteúdo que distancia a verdade e a falsidade segundo uma regra, e nem um que justifique a conclusão sem a possibilidade de que uma distribuição de estado ou informação futura a invalide. As reações à lógica clássica que ocorreram no último século pertencem a diversos grupos, e entre eles há uma campanha para reconhecer essa pobreza. Eles sugeriram que a validade é uma relação significativa, que pode ser conhecida quando estamos em condições de justificar uma derivação não apenas mecanicamente, mas por uma regra que é inclusiva o bastante para padronizar a universalidade da inferência na linguagem ou sistema de signos usados para construir esses padrões e enraizá-los como uma codificação sistemática capaz de prever o predicado "analiticidade" naquela língua.

\section{A semântica e a sensibilidade da língua: um sentido em que podemos ajustar regulativamente a teoria do significado e a teoria sobre a realidade}

Como visto anteriormente, o conteúdo da diferença com a falsidade só é adquirido quando conseguimos, mais do que a designação algébrica, determinar uma relação regrada que inverta o valor designatório de uma proposição contraditória a uma que recebeu designação de verdade. Porque se não conhecemos a regra que determina essa relação, dizer que compreendemos a sentença é uma afirmação que só vale para os usos dessa sentença em contextos altamente inofensivos e domésticos - isto é, quando os desafios de interpretação relacionados à sua inclusão em novas inferências e sentenças mais complexas não está em jogo. Nas palavras de Dummet: "nós as conhecemos suficientemente bem para usá-las corretamente em contextos familiares, mas não as entendemos completamente" (1991, p. 13). De fato, não pode ser isso que caracteriza a competência de uma compreensão, a menos que queiramos incluir papagaios treinados com "compreendedores". Isso significa que a teoria da verdade adquirida quando codificamos esse conteúdo já tem um aspecto não formal: é como a regra analítica privada de cada pessoa, e que só se compatibiliza comunicacionalmente com as regras dos demais regulativamente. Mas essa regulamentação não é supérflua: cada língua absorve as normas que são empregadas para criar, do modo orgânico, no seu interior a distância entre a verdade e a falsidade. E é o conhecimento dessa norma, que regula como línguas diferentes preveem diferentes contribuições intensionais de termos extensionalmente correlatos (sinônimos superficiais), que faz alguém um competente "compreendedor".

Definimos que qualquer tentativa de tornar a compreensão - a regra intensional para compor sentenças significativas - dependente da mera interpretação dos conectivos,

\begin{tabular}{|c|c|c|c|c|}
\hline Qovista Dialectus & Ano 10 & n. 23 & Maio - Agosto 2021 & p. $348-364$ \\
\hline
\end{tabular}


deixará o essencial de fora: "mesmo no caso da semântica clássica, estipulações diretas não exibem por si mesmas como uma sentença é determinada de acordo com sua composição" (Dummet, 1991, p. 38). Há, antes, um sistema de distanciamento entre a verdade e a falsidade que programa a linguagem para reagir de maneira regulativa às suas instâncias de sentenças verdadeiras, prevendo o seu comportamento lógico - expresso pelos conectivos - quando inseridas em contextos semânticos mais amplos ou menos familiares e domésticos. Por isso línguas diferentes crescem ou se desenvolvem de maneira diferente ao serem inoculadas com um conteúdo semântico extensionalmente idêntico. É ao reagir com seu núcleo intensional sua regra analítica - que esse conteúdo adquire um papel naquela linguagem. A lógica clássica sempre tratou como um enigma insolúvel as alterações de valor semântico geradas pela violação da lei de Leibniz (substituição salva veritate). Na concepção semântica aqui defendida, isso não é enigma algum: é exatamente aquilo que teorizamos quando queremos prever o papel profundo que um termo tem no interior da língua, o modo como esse termo pode provocar desvios estruturais de valor semântico. Nessa concepção, ao sistematizar a predição do comportamento semântico de sentenças verdadeiras, não ficamos indefesos a alterações e mudanças de valor que a mudança de contexto pode provocar e podemos construir uma teoria lógica para cada linguagem. Em outras palavras, não precisamos separar a lógica da linguagem ordinária, como fizeram os primeiros filósofos analíticos. Cada linguagem é um instrumento de regulação, norma, que permite capitalizar em uma única direção os ganhos derivados de uma escolha de instanciação das variáveis sentenciais. Quando isso é atingido, dizemos que alcançamos uma maturidade lógica para aquela linguagem, ou que ela pode gerar os códigos de condicionamento de sentenças lógicas, como "é necessário" e "é analítico". Mas essa teoria da linguagem é largamente empírica, e sujeita à revisão. O que chamamos de lógica formal é um estado ocasional de estabilidade em que tal linguagem é capaz de gerar de maneira sustentável suas proposições analíticas.

A revisão da estrutura analítica da linguagem acontece quando ela precisa se ajustar ao conteúdo semântico codificado por ganhos científicos ou culturais novos. Todo o problema é realocado assim na relação que a linguagem tem com a realidade codificada por uma simplificação científica-empírica. Chamaremos o gatilho que estabelece essa relação de sensibilidade da língua. A teoria regulativa sobre a verdade implica a seguinte tese: a de que a sensibilidade semântica de uma linguagem é determinada por quanto ela é capaz de gerar um sistema de aproveitamento de recompensas semânticas. E a verificação é, dessa forma, definida em termos negativos ou passivos, como uma inércia que alavanca o acúmulo de recompensas

\begin{tabular}{|c|c|c|c|c|}
\hline Qovista Dialectus & Ano 10 & n. 23 & Maio - Agosto 2021 & p. $348-364$ \\
\hline
\end{tabular}


verificadoras. A verificação não é determinada por fatos semânticos positivos (a designação de valores), mas pela qualidade do alcance sensível da linguagem para reagir e construir argumentos estratégicos diante de novidades semânticas. Por isso é errado confundir a verdade com a verificação: a primeira é uma designação semântica que depende de como a verificação preenche um nível mínimo de satisfação. Cada linguagem pode padronizar seus esquemas-T ou suas instâncias de sentenças verdadeiras de maneiras diferentes, mesmo se expostas aos mesmos verificadores.

O que isso mostra, contudo, é que existe um sentido em que usar a linguagem em geral envolve uma noção de interpretação cujo padrão nos permite ajustá-la ao estado de informação. Esse ajuste convencional é tudo o que existe de semântico do ponto de vista do valor que a sentença adquire neste estado de informação. Isto é, a semântica é passiva com relação à informação possível. Essa passividade semântica não foi ignorada pelos primeiros lógicos-clássicos. O que acrescentamos, se baseando nas críticas já esboçadas - e nos posicionando mais do lado não-clássico - é que o estado dessa passividade não é indiferente; diferentes linguagens são passivas ou receptivas de maneira diferente aos possíveis verificadores de sentenças. Elas crescem de maneira diferente com novidades. De modo que, se soubermos como o padrão interpretativo define o padrão de receptividade dessa linguagem, isto é, como limita as chances de ajuste de uma sentença ao estado de informação, podemos criar mais de um critério de interpretação que coincide com o lógico no sentido verifuncional. Pois certas paráfrases ou usos gramaticais irão mostrar uma insensibilidade à informação falseável, como no ilustre caso do Rei da França de Bertrand Russel, um elemento referencial com vocação para impedir a sentença "x é careca" de ser falseada pelos canais extensionais oficiais. Para escapar à conclusão de que há uma peruca ou outro ser imaginário que faria a sentença "O Rei da França é careca" verdadeira ou falsa, Russel funda a tradição profissional da análise, que, dando instrumentos para distinguir entre o escopo primário e o escopo restrito da proposição, tem sido a força filosófica subterrânea por trás da semântica moderna: “todas as proposições em que o 'Rei da França' tem uma ocorrência primária são falsas; as negativas de tais proposições são verdadeiras, mas nessas o 'Rei da França' tem uma ocorrência secundária" (Russel, 1978, p.12). O truque, do ponto de vista semântico, é manter a realidade como um tecido extensional único: se não há Reis da França para fazer a verdade ou falsidade de "Rei da França é careca", não podemos dilatar esse tecido ou dilacerar o tecido da realidade (uma semântica meramente algébrica apresenta a realidade fragmentada, sem norma) para suprir a proposição com um valor.

\begin{tabular}{|l|l|l|l|l|}
\hline Q Aovista Dialectus & Ano 10 & n. 23 & Maio - Agosto 2021 & p. 348 - 364 \\
\hline
\end{tabular}


Mas é justamente essa força subterrânea da semântica moderna que tem de ser revisada. As ambições analíticas de Russel estão intimamente conectadas ao projeto de descobrir uma estrutura de derivação de valores de verdade, e isso é parte de sua noção metafísica sobre os signos. Ele propõe a paráfrase para exprimir a sentença de um modo que, quando confrontada com a realidade, ela possa maximizar a influência desta para verificá-la ou falseá-la. Podemos chamar isso de o "grande mito semântico", para dar um título à forma mais ingênua de pressuposição semântica: a do isomorfismo estrutural entre realidade e sentença. Para Russel: "penso que há uma estrutura descobrível entre a estrutura das sentenças e a das ocorrências às quais as sentenças se referem” (1978, p. 303). Aqui, muito antes de qualquer semântica ou lógica intuicionista, o autor estabelece condições para que não se possa construir o conteúdo da distância entre verdade e falsidade, isto é, demonstrar como a distância entre elas é fundada em uma base fatual. Com isso é possível derivar estruturalmente a inversão de sinal de proposições contraditórias, preservando a lei do meio excluído. Só precisamos aumentar nosso conhecimento da estrutura relevante. A descoberta dessa estrutura inevitavelmente nos leva para questões metafísicas mais intrincadas. A questão dos universais foi um foco histórico para dar expressão a teses sobre a identidade possível entre termos gerais e a parte da realidade que corresponderia a eles. O primeiro Wittgenstein negou que fosse preciso dar expressão superficial a essa relação do geral com o particular ${ }^{6}$ : tudo o que é estrutural, para ele, já está mostrado na proposição, sem precisar ser dito ou pressuposto por ela. Mas o exercício da análise caiu em descrédito junto com a crença na relação estrutural isomórfica entre mundo e linguagem.

Nossa hipótese de interpretação sugere que Russel mantinha esses dois objetivos suficientemente emaranhados: 1. dar critérios de análise para exibir o caráter verifuncional das sentenças e 2. Exibir os traços da sentença que a correlacionam estruturalmente a um foco de apoio uniforme. Esse último objetivo é em essência semântico, o que fica claro em alguns enquadramentos do problema pelo filósofo em Significado e Verdade: "consideremos primeiramente um grupo de sentenças que contém todas um certo nome (ou um sinônimo). Todas as sentenças têm algo em comum. Podemos também dizer que seus verificadores têm algo em comum?” (1978, p. 304). Não costumamos falar da contribuição de Russel para a

6 Quando afirma "um mundo imaginário, por mais que difira do mundo real, deve ter algo - uma forma - em comum com ele" (TLP 2.002), Wittgenstein reúne sua compreensão proto-semântica (considerando que o filósofo não está diretamente engajado em um estudo de semântica) de que qualquer configuração proposicional contrafatual tem de estar ligada a um programa de verificação estrutural, que se relaciona com o mundo de maneiras semanticamente mais ou menos competentes quanto mais se atém ao mínimo estrutural que torna a realidade isomórfica à proposição.

\begin{tabular}{|l|l|l|l|l|}
\hline Qenista Qialectus & Ano 10 & n. 23 & Maio - Agosto 2021 & p. 348 - 364 \\
\hline
\end{tabular}


semântica, porque o pensador misturou com o empirismo tudo o que ele podia contribuir para essa discussão. Mas o trecho acima deriva uma tese semântica, em sua natureza: a de que existe um sentido cumulativo em que a informação verificada se insere em nossa compreensão geral de sentenças. É com base no fundamento que facilita essa acumulação que podemos compor sentenças complexas com base em outras mais simples. E a tese de Russel vai além, porque permite investigar o fundamento de adulterações dessa estrutura cumulativa, isto é, os casos em que a sentença complexa deriva apoio das mais simples de maneira dogmática ou gramaticalmente viciada.

Indo além por essa trilha, a investigação do problema sugere que ele não restringe o problema semântico, como Tarski, à característica formal que neutraliza os fundamentos comuns de sentenças previstas pela mesma teoria da verdade. É preciso investigar um fundamento de sensibilidade da codificação linguística para reagir estruturalmente a inversões de acúmulo semântico. Na verdade, o modo como o fundamento comum se manifesta na nossa codificação de sentenças é através de uma reação uniforme a verificadores de um mesmo tipo, e assim, é de se esperar que uma linguagem ontologicamente insensível ao termo "demônio" irá acumular apoio semântico a sentenças em que ele figura de modo diferente das linguagens historicamente acostumadas com o cristianismo. Em teorias puramente formais, essa diferença, contudo, é completamente ignorada. Tradutores treinados apenas formalmente estariam completamente cegos a ela. Cada linguagem é um sistema de signos programado para reagir de acordo com sua sensibilidade estrutural. Isso não envolve uma teoria fenomenológica, mas uma metafísica: sobre a relação estrutural entre o mundo e os signos. Não estamos no caminho errado, portanto, ao voltar a Russel e ao início do projeto analítico: foi nesse contexto que se estabeleceu a primeira tese semântica que levava em conta a sensibilidade de uma língua a seus possíveis verificadores, transformando a ontologia - ou a tese sobre os objetos não empiricamente verificáveis - em uma questão semântica.

\section{A inércia semântica e os elementos de um pragmatismo semântico}

O programa de regular uma semântica pela capacidade da linguagem (sua sensibilidade) de capitalizar as recompensas de cada valor de preenchimento é muito simples: se certo fundamento apoia uma sentença, o que podemos chamar de seu "valor de recompensa" não pode reverter o progresso cumulativo ao a mesma sentença ser inserida em sentenças mais complexas. Isto é, se uma sentença apoia a tese de Newton, ela não pode recusar esse apoio

\begin{tabular}{|l|l|l|l|l|}
\hline Govista Dialectus & Ano 10 & n. 23 & Maio - Agosto 2021 & p. $348-364$ \\
\hline
\end{tabular}


quando debatida em contextos mais complexos. O mesmo vale para sentenças simples ou relacionadas diretamente a um estado de informação: se as sentenças da teoria de Newton são verdadeiras em Inglês, elas precisam continuar derivando apoio dos mesmos fundamentos que a tornam verdadeira em Inglês quando traduzidas para o Português. Não é algo que começou com a teoria semântica a prática de ajustar o elemento consensual de uma discussão para sistematizar a predição de alterações no valor de verificação segundo um conteúdo. Isso é o exercício normal de qualquer indução. Mas a teoria semântica o sistematiza. Se, por exemplo, o conteúdo teórico que separa a teoria de Newton e a de Einstein pode ser unificado como fundamento comum a um grupo de sentenças, e um fundamento cumulativo comum de oposição entre essas teorias, isso pode ser previsto semanticamente. A classificação dessas sentenças mostra um fundamento proposicional capaz de gerar a diferença entre essas teorias como uma divisão no modo como seus verificadores as apoiam. Se elas têm os mesmos verificadores, é preciso prever porque eles apoiam diferentemente as teorias diferentes, ou porque recusam apoio de maneira diferente a teorias diferentes. Uma teoria semântica deve estar equipada para estudar a natureza desse comportamento, através do modo como a linguagem é sensível a ele.

Isso sugere a tese, que será apresentada na conclusão, de que a semântica é um elemento regulador que funciona em combinação com objetivos indutivos pragmáticos: as estratégias práticas de comunicação e interpretação precisam ser formuladas de modo a mostrar como cada elemento semântico ajuda a exaurir o máximo de cada estado de informação. Por elemento semântico entendemos o contexto teórico como um todo, no seguinte sentido: tudo o que é possível de se aprender por uma regra segundo o comportamento do sentido (sua regularidade em uma ou outra direção de oposição). Os elementos semânticos mais típicos estão contidos na linguagem e nas teorias científicas, constituindo em conjunto o núcleo pósmetafísico de uma cultura: de onde surgem suas verdades analíticas e sintéticas. Podemos agora dizer que o elemento semântico é o que determina a codificação do modo como um conhecimento de sentido - a compreensão do conteúdo assertórico de uma sentença - é recondicionado para se inserir em contextos mais amplos ou heterogêneos: os debates teóricos mais profundos entre candidatos rivais a paradigmas científicos.

Em outro aspecto ligado à ciência, o elemento semântico ajuda a prever alterações em conteúdos projetados sobre o futuro ou sobre mundos possíveis - é esse elemento, portanto, que determina o que a modernidade (as discussões entre o empirismo e o racionalismo) tomava de base para um conhecimento do inobservável, que é também a única base não caótica ou não anárquica em que teorias com a mesma extensão podem divergir. Naturalmente, divergências

\begin{tabular}{|l|l|l|l|l|}
\hline Govista Dialectus & Ano 10 & n. 23 & Maio - Agosto 2021 & p. $348-364$ \\
\hline
\end{tabular}


intensionais preveem diferenças que não podem ser previstas pela mera extensão. Mas esse elemento também dá uma medida para o conhecimento translinguístico de um tradutor. É o mesmo conhecimento que codifica a predição de conteúdos que irão ser reinterpretados em outra língua ou pelo complexo teórico de uma hipótese de tradução rival. É, portanto, também a base para uma teoria da comunicação, incluindo o desafio mais radical no interior desse gênero: a tradução. Segundo essa tese, um elemento de sentido - uma compreensão das condições de correção de uma sentença - cresce ou acumula material preditivo de diferentes maneiras. Um conhecimento teórico e científico do significado não envolve saber as condições de correção da sentença, mas sim saber prever os alinhamentos cumulativos que preveem se o material vai crescer em apoio de uma ou de outra linha de verificação. É a predição dessa diferença que compõe todo nosso exercício semântico. É uma tarefa das nossas teorias semânticas gerar o conhecimento da determinação da direção diferente em que cresce engorda, se altera em uma direção cumulativa uniforme - a sentença "Plutão não é um Planeta" em uma teoria física empírica e em uma astrológica. O conteúdo-ingrediente, como chamado por Dummet ${ }^{7}$, é determinado não pelo modo como contribui para a verdade das sentenças em que entra, mas pelo modo como contribui para diferentes apostas sobre como a realidade deveria ser. Na ciência moderna, o conteúdo hipotético das ciências empíricas altera o conteúdo-ingrediente de maneiras cumulativas dentro de um paradigma científico. Isso determina o seu conteúdo deontológico. Chamemos a esse alavancamento deontológico de sentido de inércia semântica. Os conteúdos ingredientes são alavancados de maneiras previsíveis - isto é, na direção acumulada por uma ou outra hipótese científica - segundo sua inércia semântica.

\section{Conclusão: a semântica como a ciência que estuda os equilíbrios de estabilidade pragmática}

Uma vez determinado isso, podemos partir para explicar a tese de que a semântica é melhor exposta, hoje, em coordenação com o pragmatismo. A fusão enunciada é desenvolvida assim: a inércia semântica que alavanca o sentido existe para ser explorada pragmaticamente

\footnotetext{
7 “Os conteúdos-ingredientes são aquilo que as teorias semânticas são programadas para explicar. A diferença entre valores não mapeados - ou se existe uma, a diferença entre valores mapeados - é uma que é irrelevante para o conteúdo assertórico. Ela serve somente para caracterizar o conteúdo ingrediente - como o conteúdo dessas sentenças afetam o conteúdo assertórico de sentenças complexas das quais é parte" (Dummet, 1991, p. 48).
}

\begin{tabular}{|l|l|l|l|l|}
\hline Ronista Dialectus & Ano 10 & n. 23 & Maio - Agosto 2021 & p. $348-364$ \\
\hline
\end{tabular}


em estratégias de interpretação, comunicação e inferência. Lembremos que o problema central para o pragmatismo de William James era decidir como eleger uma crença de preferência a outras, de acordo com o estado de informação. O filósofo acreditava que fazemos uma escolha sempre guiada pelo equilíbrio entre o desejo de segurança e o risco. Sempre cresce o risco, ou diminui a probabilidade, onde as teorias têm pouca estabilidade e seguem seus raciocínios tentando explicar demais, sem se apoiar suficientemente no que já se sabe. As estratégias de solução para problemas de significado e de verdade são um "comércio rico e ativo entre os nossos pensamentos peculiares e o grande universo das demais experiências" (James, 1989, p. 26). Ora, a visão de semântica que pintamos nesse artigo permite responder justamente ao desafio de estabilizar o valor daquilo que as informações ensinam. Quando elaboramos sistemas semânticos, não o fazemos para avaliar a correção da verdade ou falsidade de sentenças quando a relação dela com a verificação é um fato bruto; pois para isso só precisamos de uma visão direta da relação da sentença com o fato. Não acreditamos que isso seja um conhecimento semântico; pois não há nele qualquer compreensão do comportamento do sentido para influenciar diferentes alinhamentos teóricos com verificadores possíveis. É, no máximo, um conhecimento bruto do fato verificador. Mas isso não envolve qualquer domínio técnico ou controle do comportamento relevante e profundo do significado. Se chegamos ao ponto de teorizar o valor semântico da sentença, queremos saber mais do que isso, a saber: como ela desempenha um papel como contribuinte de outras sentenças, isto é, quando passa a desempenhar um papel mais fundo na linguagem. Mas também é superficial saber como isso se dá segundo a interpretação dos conectivos lógicos em uma tabela de verdade. Queremos ainda mais do que isso para dizer que sabemos operar esses significados em contextos não familiares e nem domésticos. E é nesse ponto em que o pragmatismo entra. O valor de uma teoria semântica é fundamentalmente pragmático: demonstrar o papel estratégico de uma sentença que não foi nem falseada nem verificada: "na vida prática, a verdade é valorizada principalmente como guia para a ação. E assim o principal remédio para a degeneração da probabilidade no curso de um raciocínio inferencial é aplicá-lo moderadamente" (Dummet, 1991, p. 51). Somente quem tem uma teoria semântica, ou quem gerou teoricamente uma protocompreensão desse tipo, é capaz de aplicar um princípio estratégico de seleção para crenças de maneira moderada.

Tomemos de exemplo as formas mais típicas de estratégias. As formas lógicas são a expressão estável da maximização do potencial semântico de uma linguagem. Pode-se dizer que elas abstraem e apresentam a inércia semântica em um formato estável e destacável. Porém,

\begin{tabular}{|l|l|l|l|l|}
\hline Govista Dialectus & Ano 10 & n. 23 & Maio - Agosto 2021 & p. $348-364$ \\
\hline
\end{tabular}


elas são apenas um enquadramento externo, sujeito ao constante reajuste do centro inercial regulador. Consequentemente, âmbitos de discussão científicos e, algumas vezes, linguagens naturais diferentes, hospedam sentenças com grau de contribuição semântica incongruentes e frequentemente - embora não possam mudar a forma lógica - mudam a forma como a expressão lógica se ajusta à codificação do conteúdo semântico: elas dão diferentes alavancagens inerciais, rendendo como analíticas sentenças que seriam sintéticas em outro contexto. Essa suposta instabilidade das fronteiras entre o necessário e o contingente, porém, não causa desespero metafísico se estamos protegidos pelo ponto de vista pragmático. Pois pressupomos que quando iniciamos uma estratégia de comunicação ou interpretação, não temos aquele apego intenso aos códigos que levou os semânticos do passado a acreditar que uma sentença analítica tem de construir a mesma proposição para qualquer linguagem em que ela for traduzida. A rigor, a transposição de uma linguagem para outra e as perdas de tradução não são vistas como prejuízo pelo ponto de vista pragmático. São vistas antes como sintomas gerais dos pontos de sensibilidade das línguas e das insensibilidades a acúmulo semântico que pode tornar suas ontologias incomensuráveis, ou ajustáveis apenas de uma maneira pouco mediada, isto é, com pouco apoio de uma inércia: exemplos de traduções abruptas e contra-inerciais, que carregam a ontologia rival para a linguagem adulterando o seu fundamento semântico e violando o princípio de crescimento estável das interpretações, talvez tenham sido mais comuns do que o contrário na história hermenêutica da humanidade. Protestos de violência tradutória e colonização cultural não são ilegítimos. E o mesmo pode se dar na ciência; não há motivo para achar que seria ilegítimo um neo-aristotélico protestar contra a forma abrupta e não mediada como sentenças da Física Aristotélica foram reinterpretadas ao seu valor semântico ser engolido pela Física de Galileu e Copérnico.

Do ponto de vista pragmático, inferências não são representações de verdades lógicas, que subsistiriam em um vazio formal absoluto, mas expressões do ajuste entre a codificação normativa e a capitalização do acúmulo de material semântico em uma direção ordenada: isto é, as premissas pressionam o material semântico em uma direção conclusiva irreversível. Uma inferência não é senão a expressão mais controlada de uma estratégia desse tipo: nela é codificada uma relação de ordem entre a premissa e a conclusão condicionada de modo que a realidade não pode falseá-la senão no caso em que a premissa é verificada e a conclusão falsa. Mas o "não pode” enunciado na última frase precisa de qualificação. Se não tivermos um conhecimento das pressões que geram o movimento inercial contra a qual a conclusão não pode resistir, não temos compreensão nem dos termos modais da língua, nem da

\begin{tabular}{|l|l|l|l|l|}
\hline Q Rovista Dialeatus & Ano 10 & n. 23 & Maio - Agosto 2021 & p. 348 - 364 \\
\hline
\end{tabular}


conexão formal entre premissas e conclusões: fazemos inferências como papagaios, sem entender seu significado. Inferências que correm contra o status quo da língua podem ser válidas apenas na forma, mas não se canonizam como verdades analíticas; não são estabilizadas no cânon da língua, elas sempre custam mais do que vale para empregá-las naquele contexto (teórico ou linguístico). Quando normativizamos modalmente essa relação de custos como uma de "poder", transmitimos deontologicamente ou modalmente o potencial semântico da inferência para um elemento alavancador, a linguagem, que permite acumular material semântico para novas inferências, se alinhando à visão pragmática de Dewey em Experiência e Natureza: "produz conclusões que, quando referidas às experiências da vida ordinária, (...) conseguem torná-las mais significativas, mais lúcidas para nós, e tornar nossas conexões com elas mais frutíferas" (1980, p. 9). Uma inferência explora o máximo de recompensa de um estado de informação, mas, ao contrário do que parece intuitivo ao formalismo, ela não pode e essa propriedade modal é um enunciado sobre o custo inercial - fazer isso com apoio inercial fraco da linguagem ou de maneira contra-inercial, pois sem este apoio ela não se torna significativa.

\section{Referências:}

DAVIDSON, D. Inquirires into Truth and Interpretation. Oxford University Press, 2001

DEWEY. J. Experiência e Natureza. São Paulo: Abril Cultural, 1980.

DUMMET, M. The Logical Basis of Metaphysics. Harvard University Press, 1991

HAACK, S. Filosofia das Lógicas. São Paulo: Editora Unesp, 2002.

JAMES, W. Pragmatismo. São Paulo: Abril Cultural, 1989.

QUINE, W.V.O. Sobre o que há. Ensaios. São Paulo: Abril Cultural, 1980.

RUSSEL, B. Da Denotação, Lógica e Conhecimento, São Paulo: Abril Cultural, 1978.

RUSSEL, B. Significado e Verdade. Rio de Janeiro: Zahar Editora, 1978.

STOVE, D.C. The Rationality of Induction, Clarendon Press: Oxford, 1986.

TARSKI, A. [1969]. Truth and proof. Scientific American, n. 220, p. 63-77. In: HUGHES, 1993, 1969, p. 99-125

WITTGENSTEIN. L. Tractatus Logicus-Philosophicus, São Paulo: Edusp, 2001.

\begin{tabular}{|l|l|l|l|l|}
\hline Qenista Dialectus & Ano 10 & n. 23 & Maio - Agosto 2021 & p. 348 - 364 \\
\hline
\end{tabular}

